\title{
Review and Perspectives on Pharmacological Vitreolysis
}

\author{
Francesco Bandello Carlo La Spina Lorenzo luliano Giovanni Fogliato \\ Maurizio Battaglia Parodi \\ Department of Ophthalmology, Vita-Salute University, San Raffaele Scientific Institute, Milan, Italy
}

\section{Key Words}

Vitreolysis · Plasmin · Ocriplasmin

\begin{abstract}
The vitreous is involved in multiple diseases when an incomplete posterior vitreous detachment (PVD) occurs. An incomplete PVD can lead to several pathological conditions. Such visually threatening conditions are traditionally of exclusive surgical interest. In contrast, pharmacological vitreolysis is the effort to reduce or eliminate the pathogenetic role of the vitreous solely by means of drug delivery. Here we aim to review and summarize the evidence available to date about this challenging new approach.
\end{abstract}

(c) 2013 S. Karger AG, Basel

\section{Introduction}

Sebag [1] firstly defined pharmacological vitreolytic agents as 'agents that alter the molecular organization of vitreous in an effort to reduce or eliminate its role in disease'.

The vitreous is involved in multiple diseases when an incomplete posterior vitreous detachment (PVD) occurs. Incomplete PVD is considered pathological when associ- ated with focal adhesions, causing vitreomacular traction (VMT) syndrome, vitreopapillary adhesion, tractional diabetic macular edema (DME), peripheral retinal breaks and rhegmatogenous retinal detachment, or when associated with vitreoschisis (hyaloid delamination), predisposing to epiretinal membrane, macular hole and diabetic retinopathy neovessel proliferation and recurrence (table 1) [2].

Vitreous liquefaction and posterior vitreous separation have to be pursued to obtain a safe and complete PVD through pharmacological vitreolysis.

Since the first experiments of enzymatic vitreolysis in 1998, introducing new PVD-inducing pharmacological procedures [3, 4], several vitreolytic agents have been studied to date. They can be categorized as 'enzymatic' or 'nonenzymatic', according to their mechanism of action. The majority of proposed agents belong to the first group and include plasmin, microplasmin, tissue plasminogen activator (tPA), nattokinase, chondroitinase, dispase and hyaluronidase. Nonenzymatic agents include urea/Vitreosolve ${ }^{\circledR}$ and arginine-glycine-aspartate peptides (RGD peptides).

Vitreolytic agents have been categorized by Sebag [1] on the basis of their biological effect: 'liquefactants' induce a vitreous liquefaction whilst 'interfactants' induce dehiscence at the vitreoretinal interface. The combina-

\section{KARGER}

E-Mail karger@karger.com

www.karger.com/oph (c) 2013 S. Karger AG, Basel

0030-3755/13/2304-0179\$38.00/0
Francesco Bandello, MD, FEBO

Department of Ophthalmology, San Raffaele Scientific Institute Via Olgettina, 60

IT-20132 Milan (Italy)

E-Mail bandello.francesco@hsr.it 
tion of both of these two events is fundamental to avoid retinal complications. In turn, a synchysis without syneresis may lead to retinal breaks, macular holes or retinal detachment (table 2).

\section{Vitreolytic Agents}

\section{Tissue Plasminogen Activator}

tPA is a serine protease able to convert plasminogen to plasmin, the main enzyme responsible for blood clot lysis (see plasmin section for details). tPA is believed to have a liquefactant and interfactant action [5].

Intraocular injection of tPA has been proposed for the treatment of several vitreoretinal diseases such as vitreous hemorrhage, postvitrectomy fibrin formation, submacular hemorrhage in age-related macular degeneration (AMD), retinal vascular occlusive disorders, suprachoroidal hemorrhage and endophthalmitis. Currently, intraocular tPA is only used in the treatment of postvitrectomy fibrin formation and submacular hemorrhage. For other indications, tPA has not been shown to be safe or effective.

\section{Nattokinase}

Nattokinase is serine protease produced by Bacillus subtilis and is derived from fermented soybean. It has a strong fibrinolytic affect, and is under investigation for cardiovascular and thrombotic therapy. Nattokinase has both liquefactant and interfactant actions. It has been studied in animal models [6], but conclusive data on safety and efficacy are lacking.

\section{Chondroitinase}

Chondroitinase is a protease able to degrade chondroitin sulfate, a glycosaminoglycan. It has both liquefactant and interfactant properties. In all the studies with animal models, chondroitinase failed to produce any biologically significant effect $[7,8]$.

\section{Dispase}

Dispase is a protease which cleaves fibronectin, collagen IV and, to a lesser extent, collagen I. Studies in animal and human models reported the efficacy of dispase to cleave the attachment between the posterior hyaloid and the internal limiting membrane (ILM), with minimal damage to the inner retina $[3,9]$; therefore, it has an interfactant action. Despite the results of these researches, most experimental studies reported some harmful effects. It has been suggested that dispase could trigger prolifera-
Table 1. Incomplete PVD is pathological if combined with the following conditions

\begin{tabular}{lll}
\hline Tractional & Combination & Nontractional \\
\hline VMT syndrome & DME & PDR \\
$\begin{array}{l}\text { Vitreopapillary adhesion } \\
\text { Tractional cystoid macular edema }\end{array}$ & nvAMD & nvCRVO \\
Macular hole & & \\
\hline
\end{tabular}

$\mathrm{PDR}=$ Proliferative diabetic retinopathy; $\mathrm{nv}=$ neovascular; $\mathrm{CRVO}=$ central RVO.

Table 2. Vitreolytic agents

\begin{tabular}{llll}
\hline & Interfactants & Liquefactants & Combination \\
\hline Enzymatic & \multirow{2}{*}{ Dispase } & Hyaluronidase & Plasmin \\
& & Collagenase & Microplasmin \\
& & tPA/plasminogen \\
& & Nattokinase \\
& & Chondroitinase \\
\hline Nonenzymatic & RGD peptides & Vitreosolve \\
\hline
\end{tabular}

tive vitreoretinopathy, cataract, lens subluxation and retinal toxicity $[10-16]$.

\section{Hyaluronidase}

Hyaluronidase exerts its effect by dissolving the glycosaminoglycan network of the vitreous gel, which is almost completely composed of hyaluronan. For this reason it is electively considered a liquefactant. Highly purified bovine hyaluronidase (Vitrase ${ }^{\circledR}$ ) is the only vitreolytic agent that has passed phase III trials in the management of vitreous hemorrhage $[17,18]$. Although the investigators concluded that intravitreal hyaluronidase facilitated the resolution of vitreous hemorrhage, this agent has not yet received FDA approval. Several other studies that tested hyaluronidase alone or in combination with other vitreolytic agents proved that hyaluronidase alone was ineffective in inducing PVD [19-21].

\section{Collagenase}

Collagenase is purified from Clostridium histolyticum and selectively cleaves the type II collagen, comprising the fibrillar network of the vitreous gel [22]. The resulting proteolyzed fragments are soluble, allowing for spontaneous denaturation and further degradation by nonspecific 
proteases [23]. It has mainly a liquefactant action. In animal models, collagenase succeeded in liquefying the vitreous gel but was accompanied by ILM damage and disruption of retinal architecture [24] or by histological and electrophysiological toxicity $[25,26]$. Human pilot studies of collagenase-assisted vitrectomy resulted in hemorrhages on the surface of the retina as well as evidence of digestion of retinal vasculature on proliferative membranes [27, 28].

\section{Nonenzymatic Agents}

The primary connection between the vitreous gel proteins and the retina is mediated by the integrins of the ILM. Integrins are bonded with the extracellular matrix (ECM) of the ILM by way of the RGD binding sequence [29]. This motif is present in a vast array of ECM components including laminin, fibronectin and certain collagens [30]. Synthetic RGD peptides are known to compete for integrin-binding sites, which results in disruption of integrin-ECM interaction and subsequent loosening of attachments [31,32].

There has been considerable speculation regarding a possible role of synthetic RGD peptides in disrupting vitreoretinal adhesion. For this reason they are considered as interfactants.

In a rabbit model, RGD peptides made PVD easier during vitrectomy procedure [33]. Despite this initial success, no further studies have been published.

Vitreosolve (Vitreoretinal Technologies Inc., Irvine, Calif., USA) is a proprietary nonenzymatic, urea-based molecule that has just terminated phase II/III testing protocols (PVD-301, PVD-302) in patients with nonproliferative diabetic retinopathy without preexisting PVD. Given the proprietary nature of the agent, there is little information regarding its structure or mechanism. Preliminary results from an earlier, unpublished study demonstrated PVD induction in $45 \%$ of patients following a single $12-\mathrm{mg}$ injection, with the proportion rising to $75 \%$ following a second injection 30 days later [34].

\section{Plasmin}

Plasmin is undoubtedly the most widely studied vitreolytic agent. It is a nonspecific serine protease with a critical role in fibrinolysis. Plasmin has two principal targets: it directly degrades fibrin and other extracellular matrix components, including laminin and fibronectin [35-37] and may also indirectly generate increased levels of other nonspecific proteases such as matrix metalloproteinases and elastase [38-40]. These downstream activities may enhance the primary action of plasmin in weak- ening the vitreoretinal insertion. For these properties it is capable of degrading the vitreous gel and of cleaving further ECM structures; hence, it is a liquefactant and an interfactant.

Initial animal and human studies tested the ability of plasmin to achieve a complete vitreoretinal separation alone $[37,41,42]$ or with adjunctive procedures such as vitrectomy or intraocular gas injection [43-45]. Final results showed that complete vitreous synchysis and syneresis were obtained with the adjunctive procedures or with higher doses of plasmin [46]. Several studies indeed demonstrated a correlation between both plasmin concentration, exposure time and the resultant extent of vitreoretinal separation $[37,41,43]$.

The safety profile of intravitreal plasmin in these preclinical trials was excellent, as histological examinations with light and electronic microscopy at doses up to $4 \mathrm{U}$ and with exposure times ranging from $30 \mathrm{~min}$ to 1 week did not reveal damages [11, 20, 37, 41, 42]. In addition, no functional toxicity was detected by ERG [11, 20, 45].

Plasmin is extremely unstable owing to rapid inactivation via autolysis and binding to $\alpha 2$-antiplasmin. Clinical application in human trials is complicated by the lack of an approved, commercially available plasminogen, the proenzyme required for its activation immediately prior to its use. In place of a commercial alternative, investigators have relied on the generation of autologous plasmin enzyme (APE). This process is time consuming and expensive, collecting a patient's plasma-derived plasminogen and purifying it via affinity chromatography [47].

A great number of human pilot studies used this technique to examine outcomes of plasmin-assisted vitrectomy, with doses ranging from 0.03 to $2 \mathrm{U}$, in a variety of disorders with vitreoretinal adhesion involvement:

- APE was used in the surgical treatment of pediatric traumatic macular holes [47, 48], stage 5 retinopathy of prematurity $[49,50]$ and complicated X-linked retinoschisis [51]. All reported improved anatomic outcomes compared with previously published studies.

- Plasmin-assisted vitrectomy was used to treat fullthickness macular holes in patients without preexisting PVD, with high rates of spontaneous PVD intraoperatively [52-54].

- APE prior to vitrectomy resulted in nonsignificant increases in spontaneous PVD, but in an easing of PVD surgical induction in eyes with tractional DME and complicated proliferative diabetic retinopathy [5558].

- Intravitreal APE without vitrectomy improved central macular thickness and visual acuity in eyes with macu- 
lar edema complicating branch retinal vein occlusion (RVO) [59].

- Intravitreal APE $24 \mathrm{~h}$ before vitrectomy in eyes with VMT syndrome seemed insufficient to obtain a traction resolution but resulted in easier-to-peel posterior hyaloids [60].

In this collection of pilot studies, no investigator reported a clear enzyme-related complication.

\section{Ocriplasmin}

Ocriplasmin, formerly known as microplasmin, is a recombinant product of the sole catalytic domain of human serine protease plasmin. Although being a truncated form, it retains the same proteolytic activity of plasmin, targeting major components of the vitreoretinal interface such as fibronectin and laminin. Moreover, it has some advantages over plasmin, including the following: (1) it is quarter the size of plasmin ( $22 \mathrm{vs} .88 \mathrm{kDa})$, which permits a greater penetration of vitreous and epiretinal tissues; (2) being generated by means of recombinant techniques, it ensures product sterility and eliminates the risk of microbial contamination associated with blood derivatives; (3) it permits the avoidance of the rigorous and expensive preparation of autologous plasmin, and (4) it is more stable than plasmin, which simplifies storage and timing of administration [61]. Ocriplasmin works via a two-step mechanism involving vitreoretinal separation and vitreous liquefaction. Several preclinical studies demonstrated its activity using porcine, rat, human and cadaver eyes. It has been observed that ocriplasmin causes vitreolysis and PVD in a dose- and time-dependent fashion [62]. The minimal effective dose seems to be $125 \mu \mathrm{g}$, equivalent to $2 \mathrm{U}$ of plasmin $[62,63]$.

The main body of evidence available to date comes from a series of trials sponsored by ThromboGenics and collectively called Microplasmin for Intravitreous Injection-Tractional Release without Surgical Treatment (MIVI-TRUST).

The first of these was the MIVI-I trial, a phase I/II safety study with dose escalation (25-125 $\mu \mathrm{g})$ and increasing exposure time (from $1 \mathrm{~h}$ to 1 week) [64]. A total of $60 \mathrm{pa}-$ tients were enrolled in 6 successive cohorts. All patients had VMT maculopathy for which vitrectomy was indicated, including macular edema associated with VMT, stage II-III macular hole of $<6$ months duration since symptom onset, demonstration of vitreomacular adhesion (VMA) based on preoperative optical coherence tomography (OCT), or an OCT finding of posterior hyaloid membrane inserting into the macula but with some area of clear separation visible between the retina and the pos- terior hyaloid. The results were encouraging, demonstrating that intravitreal ocriplasmin is safe and able to induce a pharmacological PVD in some patients.

The MIVI-III trial evaluated safety and efficacy of a preoperative intravitreal injection of ocriplasmin in patients undergoing vitreous surgery. A total of 125 patients scheduled for pars plana vitrectomy for the treatment of either VMT or macular hole were enrolled in this phase II placebo-controlled trial. A single intravitreal injection of ocriplasmin $(25,75$ or $125 \mu \mathrm{g})$ or placebo was administered 7 days prior to pars plana vitrectomy. The presence or absence of PVD at baseline, injection day, operative day and postinjection days 90 and 180 were evaluated. MIVI-III concluded that ocriplasmin injection at a dose of $125 \mu \mathrm{g}$ led to a greater likelihood of induction and progression of PVD than placebo injection. This study also suggested that patients receiving ocriplasmin were more likely not to require vitrectomy surgery.

The MIVI-V trial evaluated safety and efficacy of intravitreal ocriplasmin in patients diagnosed with exudative AMD with focal VMA. Patients enrolled in this study had active subfoveal choroidal neovascular membrane and received at least 3 antiangiogenic intravitreal injections, with evidence of focal VMA on OCT. The primary outcome measure is the proportion of patients with release of focal VMA by day 28. A single injection of ocriplasmin plus antivascular endothelial growth factor (antiVEGF) treatment missed the primary end point of a greater proportion of patients, achieving complete resolution of their focal VMA at day 28 versus sham control plus anti-VEGF treatment (24 vs. $12 \%$ ).

The MIVI-TRUST trial is a phase III clinical trial to compare a single intravitreal injection of ocriplasmin $(125 \mu \mathrm{g})$ with a placebo injection in patients with symptomatic VMA [65]. The primary end point was resolution of VMA at day 28. Secondary end points were total PVD and nonsurgical closure of a macular hole at 28 days, avoidance of vitrectomy and change in best-corrected visual acuity. Ocriplasmin resolved VMT and closed macular holes in significantly more patients than did injection of placebo, but was associated with a higher incidence of ocular adverse events.

In detail, 652 eyes were enrolled, of which 464 were treated with ocriplasmin and 188 with placebo. VMA resolved in $26.5 \%$ of ocriplasmin-injected eyes and in $10.1 \%$ of placebo-injected eyes. Total PVD was more prevalent among the eyes treated with ocriplasmin than among those injected with placebo (13.4 vs. 3.7\%). Nonsurgical closure of macular holes was achieved in $40.6 \%$ of ocriplasmin-injected eyes and in just $10.6 \%$ of placebo-inject- 
ed eyes. The best-corrected visual acuity was more likely to improve by a gain of at least three lines on the eye chart with ocriplasmin than with placebo. Ocular adverse events (e.g. vitreous floaters, photopsia, injection-related eye pain or conjunctival hemorrhage) occurred in $68.4 \%$ of ocriplasmin-injected eyes and in $53.5 \%$ of placebo-injected eyes, and the incidence of serious ocular adverse events was similar in the two groups.

\section{Conclusions}

Almost all the current research on enzymatic vitreolysis refers to ocriplasmin. Other agents have been abandoned due to their side effects and their limited efficacy. Other trials with microplasmin have now been completed but results are not yet available.

- Ocriplasmin for Treatment of Symptomatic Vitreomacular Adhesion including Macular Hole (OASIS) is a phase II study evaluating the treatment of symptomatic VMA including macular hole with a single $125-\mu \mathrm{g}$ intravitreal injection of ocriplasmin.

- The Microplasmin Intravitreal Administration in Participants with Uveitic Macular Edema is a phase I/II trial investigating the safety and potential efficacy of intravitreal ocriplasmin as a possible treatment for macular edema to uveitis.

- The Microplasmin in Children (MIC) Trial evaluates the safety and efficacy of intravitreal ocriplasmin as an adjunct to conventional vitrectomy for the treatment of pediatric patients under 16 years of age.

- Study of Intravitreal Microplasmin in Relieving Vitreomacular Adhesion in Neovascular Age-related Macular Degeneration (ClinTrial.gov NCT00996684). The importance of the role of the vitreous body in the pathogenesis of some other diseases is getting more and more recognized. Neovascular (wet) AMD, DME and RVO are all characterized by elevated levels of VEGF, which is known to adversely affect the clinical course of each disease. PVD might be expected to enhance the diffusion of endogenous VEGF away from the macula, and if PVD increases oxygenation this would also tend to lower macular VEGF levels. In addition, VMA may be associated with VMT that can in itself cause macular edema, which is a hallmark of all three diseases and a major cause of vision loss [66].

Observational studies of sufficient quality indicate that eyes with wet $\mathrm{AMD}$ have double the expected prevalence of VMA and are less likely to have a PVD. There is, on the contrary, insufficient evidence to conclude on the preva- lence of vitreous attachment in DME or RVO. More controlled studies of DME and RVO are needed [66].

The high prevalence rate of VMAs in dystrophies suggests that pharmacological vitreolysis may also have a role in this field [67].

\section{Future Perspectives}

Enzymatic vitreolysis has been experimented on for many years, but results remained disappointing until the introduction of microplasmin. This new drug allowed safer procedures and was ready for a day-to-day clinical setting. Data from the first randomized trials, as discussed above, are encouraging. Stronger evidence of efficacy is required to support its widespread use.

Future studies could explore the use of nonenzymatic agents, which offer the potential for vitreolysis without collateral damage to adjacent structures and the identification of particular agents for specific clinical indications. Other promising concepts deserving further exploration include the use of different doses and combinations of existing agents.

Furthermore, the possibility of combining an antiVEGF with a vitreolytic agent to counteract the pathogenesis of neovascularization is a challenging chapter that is ready to be written in the next years.

\section{Disclosure Statement}

None of the authors has a conflict of interest with the submission.

F. Bandello is an advisory board member for Allergan, Novartis Pharmaceuticals Corporation, Farmila-Thea, Bayer Schering Pharma, Pfizer, Alcon, Bausch \& Lomb, Genentech, Alimera Sciences, Sanofi-Aventis and ThromboGenics.

No financial support was received for this submission.

\footnotetext{
References $\quad D_{1}$ Sebag J: Pharmacologic vitreolysis. Retina 1998; 18:1-3.

2 Gandorfer A: Pharmacological vitreolysis: rationale, potential indications and promising agents. Retina 2012;32(suppl 2):S221-S224.

- 3 Tezel TH, Del Priore LV, Kaplan HJ: Posterior vitreous detachment with dispase. Retina 1998;18:7-15.

4 Harooni M, McMillan T, Refojo M: Efficacy and safety of enzymatic posterior vitreous detachment by intravitreal injection of hyaluronidase. Retina 1998;18:16-22.
} 
5 Kamei M, Estafanous M, Lewis H: Tissue plasminogen activator in the treatment of vitreoretinal diseases. Semin Ophthalmol 2000; 15:44-50.

6 Takano A, Hirata A, Ogasawara K, Sagara N, Inomata $\mathrm{Y}$, Kawaji T, Tanihara H: Posterior vitreous detachment induced by nattokinase (subtilisin NAT): a novel enzyme for pharmacologic vitreolysis. Invest Ophthalmol Vis Sci 2006;47:2075-2079.

7 Hermel M, Schrage NF: Efficacy of plasmin enzymes and chondroitinase $\mathrm{ABC}$ in creating posterior vitreous separation in the pig: a masked, placebo-controlled in vivo study. Graefes Arch Clin Exp Ophthalmol 2007;245: 399-406.

8 Staubach F, Nober V, Janknecht P: Enzymeassisted vitrectomy in enucleated pig eyes: a comparison of hyaluronidase, chondroitinase, and plasmin. Curr Eye Res 2004;29:261268.

-9 Oliveira LB, Tatebayashi M, Mahmoud TH, Blackmon SM, Wong F, McCuen BW 2nd: Dispase facilitates posterior vitreous detachment during vitrectomy in young pigs. Retina 2001;21:324-331.

-10 Jorge R, Oyamaguchi EK, Cardillo JA, Gobbi A, Laicine EM, Haddad A: Intravitreal injection of dispase causes retinal hemorrhages in rabbit and human eyes. Curr Eye Res 2003;26: 107-112.

11 Wang F, Wang Z, Sun X, Wang F, Xu X, Zhang X: Safety and efficacy of dispase and plasmin in pharmacologic vitreolysis. Invest Ophthalmol Vis Sci 2004;45:3286-3290.

12 Zhu D, Chen H, Xu X: Effects of intravitreal dispase on vitreoretinal interface in rabbits. Curr Eye Res 2006;31:935-946.

$\checkmark 13$ Frenzel EM, Neely KA, Walsh AW, Cameron JD, Gregerson DS: A new model of proliferative vitreoretinopathy. Invest Ophthalmol Vis Sci 1998;39:2157-2164.

14 Kralinger MT, Kieselbach GF, Voigt M, Hayden B, Hernandez E, Fernandez V, Parel JM: Experimental model for proliferative vitreoretinopathy by intravitreal dispase: limited by zonulolysis and cataract. Ophthalmologica 2006;220:211-216.

-15 Ivastinovic D, Langmann G, Aigelsreiter A, Georgi T, Wedrich A, Velikay-Parel M: Dispase-assisted vitrectomy for epiretinal prostheses implantation. Acta Ophthalmol 2012; 90:e163-e165.

-16 Tan J, Liu Y, Li W, Gao Q: Ocular pathogenesis and immune reaction after intravitreal dispase injection in mice. Mol Vis 2012;18: 887-900.

17 Kuppermann BD, Thomas EL, de Smet MD, Grillone LR, Vitrase for Vitreous Hemorrhage Study Groups: Pooled efficacy results from two multinational randomized controlled clinical trials of a single intravitreous injection of highly purified ovine hyaluronidase (Vitrase) for the management of vitreous hemorrhage. Am J Ophthalmol 2005; 140: 573-584.
8 Kuppermann BD, Thomas EL, de Smet MD, Grillone LR, Vitrase for Vitreous Hemorrhage Study Groups: Safety results of two phase III trials of an intravitreous injection of highly purified ovine hyaluronidase (Vitrase) for the management of vitreous hemorrhage. Am J Ophthalmol 2005;140:585-597.

19 Zhi-Liang W, Wo-Dong S, Min L, Xiao-Ping $\mathrm{B}$, Jin J: Pharmacologic vitreolysis with plasmin and hyaluronidase in diabetic rats. Retina 2009;29:269-274.

20 Wang ZL, Zhang X, Xu X, Sun XD, Wang F: PVD following plasmin but not hyaluronidase: implications for combination pharmacologic vitreolysis therapy. Retina 2005;25: 38-43.

21 Narayanan R, Kuppermann BD: Hyaluronidase for pharmacologic vitreolysis. Dev Ophthalmol 2009;44:20-25.

22 Bishop PN: Vitreous as a substrate for vitreolysis. Dev Ophthalmol 2009;44:7-19.

23 Mandl I: Collagenase. Science 1970;169: 1234-1238.

24 O’Neill R, Shea M: The effects of bacterial collagenase in rabbit vitreous. Can J Ophthalmol 1973;8:366-370.

25 Moorhead LC, Chu HH, Garcia CA: Enzymeassisted vitrectomy with bacterial collagenase. Time course and toxicity studies. Arch Ophthalmol 1983;101:265-274.

-26 Moorhead LC, Redburn DA, Kirkpatrick DS, Kretzer F: Bacterial collagenase. Proposed adjunct to vitrectomy with membranectomy. Arch Ophthalmol 1980;98:1829-1839.

27 Moorhead LC, Radtke N: Enzyme-assisted vitrectomy with bacterial collagenase. Pilot human studies. Retina 1985;5:98-100.

-28 Takahashi M, Trempe CL, Maguire K, McMeel JW: Vitreoretinal relationship in diabetic retinopathy. A biomicroscopic evaluation. Arch Ophthalmol 1981;99:241-245.

29 Elner SG, Elner EM: The integrin superfamily and the eye. Invest Ophthalmol Vis Sci 1996; 37:696-701.

30 Hynes RO: Integrins: versatility, modulation, and signaling in cell adhesion. Cell 1992;69: $11-25$.

- 31 Gehlsen KR, Argraves WS, Pierschbacher MD, Ruoslahti E: Inhibition of in vitro tumor cell invasion by Arg-Gly-Asp-containing synthetic peptides. J Cell Biol 1988;106:925-930.

-32 Pierschbacher MD, Ruoslahti E: Influence of stereochemistry of the sequence Arg-GlyAsp-Xaa on binding specificity in cell adhesion. J Biol Chem 1987;262:17294-17298.

-33 Oliveira LB, Meyer CH, Kumar J, Tatebayashi M, Toth CA, Wong F, Epstein DL, McCuen BW 2nd: RGD peptide-assisted vitrectomy to facilitate induction of a posterior vitreous detachment: a new principle in pharmacological vitreolysis. Curr Eye Res 2002;25:333-340.

34 Karageozian HL: Determine the safety and efficacy of Vitreosolve ${ }^{\circledR}$ administered intravitreally to induce a complete posterior vitreous detachment (PVD) in nonproliferative diabetic retinopathy human subjects. Invest Ophthalmol Vis Sci 2005;46(suppl):5453.
35 Liotta LA, Goldfarb RH, Brundage R, Siegal GP, Terranova V, Garbisa S: Effect of plasminogen activator (urokinase), plasmin, and thrombin on glycoprotein and collagenous components of basement membrane. Cancer Res 1981;41:4629-4636.

36 Uemura A, Nakamura M, Kachi S, Nishizawa Y, Asami T, Miyake Y, Terasaki H: Effect of plasmin on laminin and fibronectin during plasmin-assisted vitrectomy. Arch Ophthalmol 2005; 123:209-213.

37 Li X, Shi X, Fan J: Posterior vitreous detachment with plasmin in the isolated human eye. Graefes Arch Clin Exp Ophthalmol 2002;240: 56-62.

-38 Takano A, Hirata A, Inomata Y, Kawaji T, Nakagawa K, Nagata S, Tanihara H: Intravitreal plasmin injection activates endogenous matrix metalloproteinase- 2 in rabbit and human vitreous. Am J Ophthalmol 2005; 140: 654-660.

-39 Baramova EN, Bajou K, Remacle A, L'Hoir C, Krell HW, Weidle UH, Noel A, Foidart JM: Involvement of $\mathrm{PA} /$ plasmin system in the processing of pro-MMP-9 and in the second step of pro-MMP-2 activation. FEBS Lett 1997;405:157-162.

40 Wachtfogel YT, Abrams W, Kucich U, Weinbaum G, Schapira M, Colman RW: Fibronectin degradation products containing the $\mathrm{cy}$ toadhesive tetrapeptide stimulate human neutrophil degranulation. J Clin Invest 1988; 81:1310-1316.

41 Gandorfer A, Putz E, Welge-Lüssen U, Grüterich M, Ulbig M, Kampik A: Ultrastructure of the vitreoretinal interface following plasmin assisted vitrectomy. Br J Ophthalmol 2001;85:6-10.

42 Gandorfer A, Priglinger S, Schebitz K, Hoops J, Ulbig M, Ruckhofer J, Grabner G, Kampik A: Vitreoretinal morphology of plasmintreated human eyes. Am J Ophthalmol 2002; 133:156-159.

43 Verstraeten TC, Chapman C, Hartzer M, Winkler BS, Trese MT, Williams GA: Pharmacologic induction of posterior vitreous detachment in the rabbit. Arch Ophthalmol 1993;111:849-854.

44 Gandorfer A, Ulbig M, Kampik A: Plasminassisted vitrectomy eliminates cortical vitreous remnants. Eye (Lond) 2002;16:95-97.

45 Hikichi T, Yanagiya N, Kado M, Akiba J, Yoshida A: Posterior vitreous detachment induced by injection of plasmin and sulfur hexafluoride in the rabbit vitreous. Retina 1999;19:55-58.

46 Sumi H, Hamada H, Tsushima H, Mihara H, Muraki $\mathrm{H}$ : A novel fibrinolytic enzyme (nattokinase) in the vegetable cheese Natto; a typical and popular soybean food in the Japanese diet. Experientia 1987;43:1110-1111.

47 Margherio AR, Margherio RR, Hartzer M, Trese MT, Williams GA, Ferrone PJ: Plasmin enzyme-assisted vitrectomy in traumatic pediatric macular holes. Ophthalmology 1998; 105:1617-1620. 
48 Wu WC, Drenser KA, Trese MT, Williams GA, Capone A: Pediatric traumatic macular hole: results of autologous plasmin enzymeassisted vitrectomy. Am J Ophthalmol 2007; 144:668-672.

49 Tsukahara Y, Honda S, Imai H, Kondo N, Fujii S, Yokoyama N, Hirata A, Kawaji T, Fukushima M, Tanihara H, Negi A: Autologous plasmin-assisted vitrectomy for stage 5 retinopathy of prematurity: a preliminary trial. Am J Ophthalmol 2007;144:139-141.

50 Wu WC, Drenser KA, Lai M, Capone A, Trese MT: Plasmin enzyme-assisted vitrectomy for primary and reoperated eyes with stage 5 retinopathy of prematurity. Retina 2008;28(suppl 3):S75-S80.

51 Wu WC, Drenser KA, Capone A, Williams GA, Trese MT: Plasmin enzyme-assisted vitreoretinal surgery in congenital X-linked retinoschisis: surgical techniques based on a new classification system. Retina 2007;27:1079-1085.

>52 Trese MT, Williams GA, Hartzer MK: A new approach to stage 3 macular holes. Ophthalmology 2000;107:1607-1611.

53 Rizzo S, Pellegrini G, Benocci F, Belting C, Baicchi U, Vispi M: Autologous plasmin for pharmacologic vitreolysis prepared 1 hour before surgery. Retina 2006;26:792-796.

54 Sakuma T, Tanaka M, Inoue M, Mizota A, Souri M, Ichinose A: Efficacy of autologous plasmin for idiopathic macular hole surgery. Eur J Ophthalmol 2005;15:787-794.
55 Asami T, Terasaki H, Kachi S, Nakamura M, Yamamura K, Nabeshima T, Miyake Y: Ultrastructure of internal limiting membrane removed during plasmin-assisted vitrectomy from eyes with diabetic macular edema. Ophthalmology 2004;111:231-237.

56 Azzolini C, D’Angelo A, Maestranzi G, Codenotti M, Della Valle P, Prati M, Brancato R: Intrasurgical plasmin enzyme in diabetic macular edema. Am J Ophthalmol 2004;138: 560-566.

57 Sakuma T, Tanaka M, Inoue J, Mizota A, Souri M, Ichinose A: Use of autologous plasmin during vitrectomy for diabetic maculopathy. Eur J Ophthalmol 2006;16:138-140.

58 Hirata A, Takano A, Inomata Y, Yonemura N, Sagara N, Tanihara H: Plasmin-assisted vitrectomy for management of proliferative membrane in proliferative diabetic retinopathy: a pilot study. Retina 2007;27:1074-1078.

59 Udaondo P, Díaz-Llopis M, García-Delpech $\mathrm{S}$, Salom D, Romero FJ: Intravitreal plasmin without vitrectomy for macular edema secondary to branch retinal vein occlusion. Arch Ophthalmol 2011;129:283-287.

60 Codenotti M, Maestranzi G, De Benedetto U, Querques G, Della Valle P, Iuliano L, Fogliato G, D’Angelo A, Bandello F: Vitreomacular traction syndrome: a comparison of treatment with intravitreal plasmin enzyme versus spontaneous vitreous separation without treatment. Eye (Lond) 2013;27:22-27.
61 Schneider EW, Johnson MW: Emerging nonsurgical methods for the treatment of vitreomacular adhesion: a review. Clin Ophthalmol 2011;5:1151-1165.

-62 Tsui I, Pan CK, Rahimy E, Schwartz SD: Ocriplasmin for vitreoretinal diseases. J Biomed Biotechnol 2012;2012:354979.

63 de Smet MD, Valmaggia C, Zarranz-Ventura J, Willekens B: Microplasmin: ex vivo characterization of its activity in porcine vitreous. Invest Ophthalmol Vis Sci 2009;50:814-819.

64 de Smet MD, Gandorfer A, Stalmans P, Veckeneer M, Feron E, Pakola S, Kampik A: Microplasmin intravitreal administration in patients with vitreomacular traction scheduled for vitrectomy: the MIVI I trial. Ophthalmology 2009;116:1349-1355.

65 Stalmans P, Benz MS, Gandorfer A, Kampik A, Girach A, Pakola S, Haller JA, MIVITRUST Study Group: Enzymatic vitreolysis with ocriplasmin for vitreomacular traction and macular holes. N Engl J Med 2012;367: 606-615.

66 Jackson TL, Nicod E, Angelis A, Grimaccia F, Prevost AT, Simpson AR, Kanavos P: Vitreous attachment in age-related macular degeneration, diabetic macular edema, and retinal vein occlusion: a systematic review and metaanalysis. Retina 2013;33:1099-1108.

67 Pierro L, Triolo G, Parodi MB, et al: Spectral domain OCT findings in patients with retinitis pigmentosa. Ophthalmic Res, in press. 